\title{
Multi-trait and random regression mature weight heritability and breeding value estimates in Nelore cattle
}

\author{
A.A. Boligon ${ }^{1}$, M.E.Z. Mercadante ${ }^{2}$, F. Baldi ${ }^{1}$, R.B. Lôbo ${ }^{3}$ and L.G. Albuquerque ${ }^{1 \#}$ \\ ${ }^{1}$ Faculdade de Ciências Agrárias e Veterinárias, UNESP. 14884-000-Jaboticabal (SP), Brazil \\ ${ }^{2}$ Instituto de Zootecnia, Estação Experimental de Zootecnia de Sertãozinho, Cx. 63, \\ 14.160-000-Sertãozinho (SP), Brazil \\ ${ }^{3}$ Faculdade de Medicina de Ribeirão Preto, USP. Brazil
}

\begin{abstract}
Mature weight breeding values were estimated using a multi-trait animal model (MM) and a random regression animal model (RRM). Data consisted of 82064 weight records from 8145 animals, recorded from birth to eight years of age. Weights at standard ages were considered in the MM. All models included contemporary groups as fixed effects, and age of dam (linear and quadratic effects) and animal age as covariates. In the RRM, mean trends were modelled through a cubic regression on orthogonal polynomials of animal age and genetic maternal and direct and maternal permanent environmental effects were also included as random. Legendre polynomials of orders 4, 3, 6 and 3 were used for animal and maternal genetic and permanent environmental effects, respectively, considering five classes of residual variances. Mature weight (five years) direct heritability estimates were 0.35 (MM) and 0.38 (RRM). Rank correlation between sires' breeding values estimated by MM and RRM was 0.82 . However, selecting the top $2 \%$ (12) or $10 \%$ (62) of the young sires based on the MM predicted breeding values, respectively $71 \%$ and $80 \%$ of the same sires would be selected if RRM estimates were used instead. The RRM modelled the changes in the (co)variances with age adequately and larger breeding value accuracies can be expected using this model.
\end{abstract}

Keywords: Beef cattle, different models, growth

\# Corresponding author. E-mail: lgalb@fcav.unesp.br

\section{Introduction}

In Brazil, animal breeding programmes for beef cattle breeds have prioritized the selection of growth traits such as weight or weight gain at early ages. These traits are easy to obtain, with heritability estimates of medium to high, thus responding rapidly to selection. However, they show positive genetic correlations with mature weight (Meyer, 1995; Meyer et al., 2004; Boligon et al., 2009). Generally, selection is directed to increase animal weight, which consequently increases the animal size at all ages. Mature weight is an important trait since the cows are kept under extensive range conditions. Studies have demonstrated the existence of a positive correlation between mature size and feed intake. Consequently, large animals have higher maintenance requirements with increasing production costs than smaller ones (Euclides Filho, 2001).

In this context, to maintain desirable mature size it is necessary to include mature weight selection indices of beef cattle. However, a difficulty in using this trait in genetic evaluations is the scarcity of weight records obtained after two years of age. Moreover, the best way for analysis, these records have to be defined (Boligon et al., 2008). In general, for the genetic evaluation of beef cattle, multi-trait models, which combine information on correlated traits to predict the genetic merit of animals for many traits simultaneously, are applied. The use of multi-trait models for genetic evaluations of mature weight, which include weights recorded before selection, allows for the recovering of part of the genetic variance lost due to selection (Meyer, 1995; Boligon et al., 2008). With these models weights have to be adjusted to standard ages at weaning, yearling and for final weights.

Recently, there has been an increasing interest in random regression models for traits that are recorded repeatedly during the animal's life, the so-called longitudinal data. The use of random regression models allows for the inclusion of all records and may increase the accuracy of predicting breeding values (Albuquerque \& Meyer, 2001; Tier \& Meyer, 2004).

The objective of this study was to compare estimated breeding values of the mature weight of Nelore cows, using the traditional multi-trait and random regression models. 


\section{Materials and Methods}

Data consisting of 82064 weight records from 8145 animals were obtained from the Genetic Breeding Programme of Nelore Cattle (PMGRN). This genetic evaluation programme started in 1987. Animals participating in the programme were weighed every $90 \mathrm{~d}$ from birth to $550 \mathrm{~d}$ of age, and those remaining in the herds for reproduction were weighed routinely at the same intervals. Calves were born throughout the year, though more frequent in spring and summer. Animals were weaned at $240 \mathrm{~d}$ of age, on average. Only records of animals that were produced through artificial insemination, reared on pasture without supplemental feed and who were weaned by their biological mothers were considered.

For the multi-trait model (MM) birth weight, weaning weight, weight at 550 days of age, and weights at two, three and five years of age, were considered. Genetic additive direct (for all weights), genetic maternal (for weaning weight), and maternal permanent environmental (for birth weight, weaning weight and weight at 550 days of age) were considered as random effects. A contemporary group (farm, year and season of birth) was included in the model as a fixed effect. Linear and quadratic effects of age of animal at recording (except for birth weight), and dam age at calving were included as covariates.

In the random regression model (RRM) mean trends were modelled using a cubic regression on orthogonal polynomials of animal age. Direct and maternal genetic and permanent environmental effects were modelled by random regression on Legendre polynomials of age, with orders of 4, 3, 6 and 3, respectively. For residual variances five age classes were considered: 0, 1 - 216, 217 - 660, 661 - 960 and 961 - 2920 days of age.

For the RRM, the contemporary group for records from birth to three years of age was defined including animals born on the same farm, year and season of birth, and belonging to the same class of age at recording (birth and every 45 days of age, so that the age variation within contemporary group was not longer than $45 \mathrm{~d}$ ). The contemporary group for records taken after three years of age was defined by farm, year and season of birth, and year and season of recording. Contemporary groups with less than eight animals were also excluded, leaving 2693 groups. All animals had at least five weight records. The contemporary group was included as a fixed effect and dam age at calving (in days) as a covariate (linear and quadratic effects).

For both models (MM and RRM), weight records out of the range given by the mean of the contemporary group \pm 3 standard deviations were excluded. The mature weight was considered as weight at five years of age.

The covariance components were estimated by "restricted maximum likelihood" using the WOMBAT software (Meyer, 2006). In all of the analyses, a pedigree file containing the identification of the animal, sire, and dam was used, with a total of 26924 animals in the relationship matrix. Spearman correlation coefficients between mature weight breeding values estimated by MM and RRM were calculated.

\section{Results and Discussion}

The observed means and standard deviations for weights from birth to eight years of age are shown in Figure 1. The weights increased until approximately five years of age. The weight means of 5-yr-old or older cows (470 kg) are similar to those reported in the literature for mature weight of Nelore cows (Rosa et al., 2001; Pedrosa et al., 2006).

The direct heritability estimates for mature weight (five years) were 0.35 and 0.38 , using $\mathrm{MM}$ and RRM, respectively. These results agree with those described in the literature for Nelore cattle (Mercadante et al., 2004; Pedrosa et al., 2006; Boligon et al., 2008), which vary from 0.30 to 0.53 . These estimates suggest that mature weight will respond rapidly to individual selection. However, since this trait is measured late in the animal's life one could not expect a high genetic gain due to large generation intervals. Moreover, in order to find the most adequate weight for a given production system, economic selection indices including this trait will have to be developed. Similar heritability estimates were also reported for different cattle breeds. Nephawe (2004) evaluating mature weight of Bonsmara cows with ages ranging from two to 11 years, reported heritability estimates varying from 0.39 to 0.47 using RRM, and were consistent with the estimate of 0.41 obtained using a simple repeatability model. Meyer (1999), also using RRM, reported estimates of heritability from 0.37 to 0.57 for Hereford cows, and from 0.42 to 0.49 for Wokalups. 


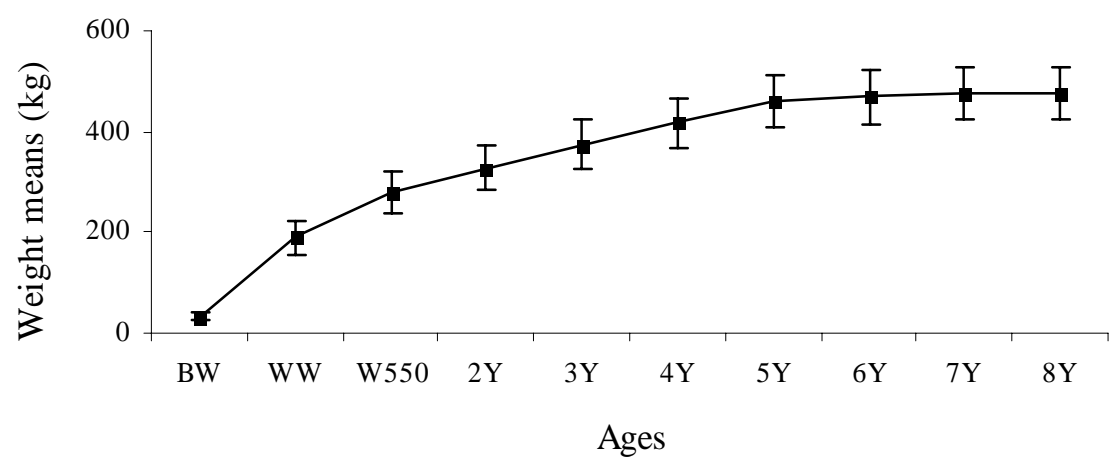

Figure 1 Means (“) and standard deviations (bar) for birth weight (BW), weaning weight (WW), weight at 550 days of age (W550), and weights at 2, 3, 4, 5, 6, 7 and 8 years (Y) of age.

The RRM approach provides more information than the usual MM analysis. For example, with RRM it is possible to estimate breeding values for the animal growth curve as a whole, whereas the MM will only provide these at particular points of the growth curve. Table 1 shows mature weight breeding value means using different models. Mature weight breeding value means predicted by RRM were larger than those obtained with MM, probably as a result of the slightly higher heritability estimates and better use of information with RRM.

Our results agree with those from Nephawe (2004) who concluded that selection for mature weight could be effective and that RRM could be useful. However, according to the author, given the complexity of the RRM, for practical purposes a simple repeatability model might be an acceptable approximation for prediction of breeding values.

Table 1 Mean, standard deviation (SD), minimum and maximum mature weight breeding value estimates in Nelore cattle

\begin{tabular}{ccccc}
\hline Models $^{1}$ & Mean $^{2}$ & SD & Minimum & Maximum \\
\hline MM & 1.24 & 1.84 & -8.64 & 13.21 \\
RRM & 1.67 & 2.06 & -9.72 & 15.47
\end{tabular}

${ }^{1} \mathrm{MM}$ - multi-trait model; RRM - random regression model; ${ }^{2} \mathrm{~kg}$.

The sire rank correlations between breeding values for mature weight estimated by MM and RRM were 0.82 . Selecting the top $2 \%$ (12) or $10 \%$ (62) of the sires based on the MM predicted breeding values, $71 \%$ and $80 \%$ of the same sires, respectively, would be selected if RRM estimates were used instead (Table 2). Although considering all sires the rank correlation was high, important changes in sire rank occurred when selection intensity increased, which could affect selection response.

Table 2 Number and percentage of sires which would be the same if selected based on mature weight breeding values estimated by multi-trait or random regression models

\begin{tabular}{ccc}
\hline \multirow{2}{*}{ Selection intensity } & \multicolumn{2}{c}{ Random regression models } \\
\cline { 2 - 3 } & Number of selected sires & Percentage of selected sires \\
$2 \%(12$ animals $)$ & 8 & $71 \%$ \\
$10 \%(62$ animals $)$ & 50 & $80 \%$ \\
$20 \%(123$ animals $)$ & 102 & $83 \%$ \\
$50 \%(308$ animals $)$ & 271 & $88 \%$ \\
\hline
\end{tabular}


It is expected that RRM produce more accurate genetic parameter estimates and predictions of genetic values than MM. This gain in accuracy is more important for young bulls, with none or just a few mature weight progeny information. Meyer (2004) working with simulation, reported that the RRM models showed higher accuracy (up to 8.3\%), measured by the correlation between true and estimated breeding values, compared to a MM. The author attributed this to better modelling of variances and genetic parameters provided by RRM. Future research should concentrate on quantifying how much would be gained in terms of accuracy and response to selection by applying RRM instead of MM, considering a limited number of points such as birth, weaning, yearling, and final weights.

\section{Conclusion}

The mature weight heritability estimate obtained with a random regression model was slightly higher than that estimated with a multi-trait model, with a corresponding effect on genetic gain. Differences in sire rank for mature weight are expected when applying multi-trait or random regression models, mainly with high selection intensity.

\section{Acknowledgments}

The authors wish to acknowledge Fundação de Amparo à Pesquisa do Estado de São Paulo (FAPESP) and Conselho Nacional de Desenvolvimento Científico e Tecnológico (CNPq), Brazil. We are indebted to the Associação Nacional de Criadores e Pesquisadores (ANCP) for the use of their data.

\section{References}

Albuquerque, L.G. \& Meyer, K., 2001. Estimates of covariance functions for growth from birth to $630 \mathrm{~d}$ of age in Nelore cattle. J. Anim. Sci. 79, 2776-2789.

Boligon, A.A., Albuquerque, L.G., Mercadante, M.E.Z. \& Lobo, R.B., 2008. Models for genetic evaluation of Nelore cattle mature body weight. J. Anim. Sci. 86, 2840-2844.

Boligon, A.A., Albuquerque, L.G., Mercadante, M.E.Z. \& Lobo, R.B., 2009. Herdabilidades e correlações entre pesos do nascimento à idade adulta em rebanhos da raça Nelore. Rev. Bras. Zoot. (in press).

Euclides Filho, K., 2001. Proc. 2 Simpósio Nacional Produção e Gerenciamento da Pecuária de Corte: 196-208.

Mercadante, M.E.Z., Razook, A.G., Trovo, J.B.F., Cyrillo, J.N.S.G. \& Figueiredo, L.A., 2004. Parâmetros genéticos do peso no início da estação de monta, considerando indicativo do peso adulto de matrizes Nelore. Rev. Bras. Zootec. 33, 1135-1144.

Meyer, K., 1995. Estimates of genetic parameters for mature weight of Australian beef cows and its relationships to early growth and skeletal measures. Livest. Prod. Sci. 44, 125-137.

Meyer, K., 1999. Estimates of genetic and phenotypic covariance functions for postweaning growth and mature weight of beef cows. J. Anim. Breed. Genet. 116, 181-205.

Meyer, K., 2004. Scope for a random regression model in genetic evaluation of beef cattle for growth. Livest. Prod. Sci. 86, 69-83.

Meyer, K., 2006. "WOMBAT" - Digging deep for quantitative genetic analyses by restricted maximum likelihood. Proc. $8^{\text {th }}$ World Congr. Genet. Appl. Livest. Prod., Belo Horizonte, Brazil, CD-ROM.

Meyer, K., Johnston, D. \& Graser, H., 2004. Estimates of the complete genetic covariance matrix for traits in multi-trait genetic evaluation of Australian Hereford cattle. Aust. J. Agric. Res. 55, 195-210.

Nephawe, K.A., 2004. Application of random regression models to the genetic evaluation of cow weight in Bonsmara cattle of South Africa. S. Afr. J. Sci. 34, 166-173.

Pedrosa, V.B., Eler, J.P., Silva, J.A. IIV., Formigoni, I.B., Mourão, G.B., Bueno, R.S., Ferraz, J.B.S., Ribeiro, S. \& Zampar, A., 2006. Heritability estimation for mature weight in Nellore cattle. Proc. $8^{\text {th }}$ World Congr. Genet. Appl. Livest. Prod., Belo Horizonte, Brazil, CD-ROM.

Rosa, A.N., Lobo, R.B., Oliveira, H.N., Bezerra, L.A.F., \& Borjas, A.R., 2001. Peso adulto de matrizes em rebanhos de seleção da raça Nelore no Brasil. Rev. Bras. Zootec. 30, 1027-1036.

Tier, B. \& Meyer, K., 2004. Approximating prediction error covariances in multiple-trait and random regression models. J. Anim. Breed. Genet. 121, 77-89. 